\title{
Comparison of Agar and an Agitated, Thin-film, Liquid System for Micropropagation of Ornamental Elephant Ears
}

\author{
Jeffrey Adelberg ${ }^{1}$ and Joe Toler ${ }^{2}$ \\ Clemson University, Clemson, SC 29634
}

Additional index words. Alocasia macrorrhizos, bioreactor, Colocasia esculenta refractometer, sugar, taro, tissue culture

\begin{abstract}
Micropropagation of black-stemmed elephant ear (C. esculenta (L.) Schott 'Fontanesii')' and upright elephant ear (A. macrorrhizos G. Don) were compared in semi-solid agar media and agitated, liquid thin-film bioreactor vessels at four explant densities (33, 100, 165, and 330 explants/L of media) using two growth regulator combinations: 1) $1 \mu \mathrm{M}$ benzylaminopurine (BA) — growth medium, and 2) $3 \mu \mathrm{M}$ BA plus $3 \mu \mathrm{M}$ ancymidol—multiplication medium. The thin-film liquid system outperformed agar culture for most measured responses. Some exceptions were relative dry weights at higher explant densities and multiplication rate of Colocasia. When the thin-film liquid system was compared to agar culture, Alocasia explants produced their greatest biomass and had the least residual sugar at the highest explant density. Alocasia explants multiplied most rapidly and had the greatest relative dry weight on liquid media at the low explant densities. Alocasia plants were larger in growth medium than multiplication medium and larger in liquid medium than agar medium. When compared to agar, Colocasia in the thin-film liquid system produced the greatest biomass at the highest explant density in growth medium, had the greatest relative dry weight at the lowest explant density, and used the most sugar at the highest explant density. Alocasia and Colocasia would likely produce greater fresh and dry weight at the highest explant density if additional sugar were supplied during thin-film culture. Greater growth in thin-film culture of Alocasia and Colocasia is due in part, to greater availability of sugar in liquid compared to agar medium.
\end{abstract}

Elephant ears (Alocasia macrorrhizos, Colocasia esculenta, $C$. affinis, and $C$. gigantea) are popular ornamental landscape plants because of their large leaf blades on long petioles. Although traditionally grown in zones 8 to 10 (USDA Hardiness Zone Map), modern cultivars have been selected for cold-hardiness and are now grown in zone 7b (Avent, 2001). Vegetative propagation is necessary to maintain desirable ornamental characteristics such as the anthocyanin patterns on leaves and petioles. Micropropagation has filled much of the recent demand for modern landscape varieties. The commercial technique for micropropagation uses semi-solid agar medium similar to that used for other ornamental perennial plants $(R$. Strode, Agri-Starts I, Apopka, Fla., personal communication).

The carbohydrate-rich corms of Colocasia esculenta (L.) Schott are grown in the tropics as a staple commonly called taro. Taro cultivars

Received for publication 29Apr. 2003. Accepted for publication 6 Oct. 2003. Publication no. 4871 of the South Carolina Agriculture Research and Forestry Service. We thank Jacqueline Naylor-Adelberg and her staff at Southern Sun BioSystems' Norris Beta-site for their assistance. Use of company or product names by Clemson University does not imply approval or recommendation of the product to the exclusion of others that may be suitable.

${ }^{1}$ Department of Horticulture. To whom reprints requests should be addressed; e-mail jadlbrg@clemson. edu.

${ }^{2}$ Department of Experimental Statistics. are maintained by vegetative propagation. Micropropagation has been commercially scaled to produce clean planting stock of new varieties with superior flour quality and disease resistance (Trujilo, 2002). Use of cytokinin growth regulators, BA or thidiazuron, on a stiff agar gel $(1.3 \% \mathrm{w} / \mathrm{v})$ was shown by Chand et al. (1999) to promote rapid shoot multiplication for planting of pathogen-free superior clones. In contrast, Zhou et al. (1999) induced corm formation in shaker flasks containing varying volumes of liquid media with combinations of high sugar levels ( $8 \%$ to $10 \%$ w/v), high BA levels ( 22 to $44 \mu \mathrm{M})$ and the growth retardant, palactrobutazol, concluding that agitated, thin layers of liquid media in shaker flasks with high concentrations of sugar, BA and palactrobutrazol was the most economical way to produce the largest corms for direct field planting of diploid taro.

Temporary immersion systems (TIS) have been observed to improve shoot proliferation, biomass, and shoot quality, when compared to conventional micropropagation of twenty plant species (Etienne and Barthouly, 2002). Reduced production costs in terms of labor, facilities and numbers of containers were noted. The agitated-liquid, tilting and rocking machines developed by Harris and Mason (1983) were the first TIS systems, but to our knowledge were not used in published literature since that initial report. A simpler rocker system was recently developed that mechanically tilts articulated shelves to create small wave fronts and alternately bathe and aerate shoot buds in rectangular vessels with a large growth surface (Adelberg and Simpson, 2002). Efficiencies in facility and labor utilization with increased multiplication rates depend upon several factors including design of system, vessel dimensions and density of explants (Adelberg, 2004; Etienne and Bethouly, 2002; Levin and Tanny, 2003).

Technician time in the transfer process is a critical component of efficiency (Adelberg, 2004). Long petioles and large leaf blades in liquid medium, make elephant ear plantlets that are wet, floppy and difficult to aseptically remove from the vessel. This slows the transfer process during subculture in multiplication phase. A multiplication medium containing the gibberellin-antagonist, ancymidol, was introduced to reduce plant size during multiplication (stage II) subculture.

The current study examines effects of explant density and plant growth regulators on in vitro growth and multiplication of black-stemmed elephant ear (C. esculenta var. 'Fontanesii') and upright elephant ear (Alocasia macrorrhizos) comparing growth and multiplication on semi-solid agar medium with the rocker-an agitated thin-film liquid system. We also relate sugar use to biomass production and plant quality for these important species of elephant ears.

\section{Materials and Methods}

Plant material. Black-stemmed elephant ear (C. esculenta var. 'Fontanesii')' and upright elephant ear (Alocasia macrorrhizos) were obtained from stage II cultures maintained for at least 12 months. Plantlets were sub-cultured every 6 weeks by carefully trimming leaves and roots to individual single-bud divisions on liquid growth medium. The liquid growth medium was modified Murashige and Skoog (MS) medium (Murashige and Skoog, 1962) that included per liter, $170 \mathrm{mg} \mathrm{NaH} \mathrm{PO}_{4}$, increased $\mathrm{CuSO}_{4} \cdot 5 \mathrm{H}_{2} \mathrm{O}$ concentration to $25 \mathrm{mg}$, $1.0 \mathrm{mg}$ per liter glycine, $100.0 \mathrm{mg}$ myo-inositol, $0.25 \mathrm{mg}$ nicotinic acid, $0.25 \mathrm{mg}$ pyridoxine hydrochloride, $0.05 \mathrm{mg}$ thiamine hydrochloride, $92 \mathrm{mg}$ adenine hemisulfate and $50 \mathrm{~g}$ sucrose. Medium $\mathrm{pH}$ was adjusted to 5.7 with $\mathrm{NaOH}$ before being dispensed. Liquid Lab culture vessels (Southern Sun Biosystems, Hodges, SC) containing $200 \mathrm{~mL}$ of medium and 15 to 20 explants were maintained on a thin-film rocker system (Adelberg and Simpson, 2002) that produced a $1-\mathrm{cm}$ pitch every $15 \mathrm{~min}$ (with a $1 \mathrm{rpm}$ cam). Experiments were conducted with $16 \mathrm{~h}$ photoperiod of 25 to $35 \mu \mathrm{mol} \cdot \mathrm{m}^{-2} \cdot \mathrm{s}^{-1}$ PPF provided by cool-white fluorescent lamps at $24 \pm 2^{\circ} \mathrm{C}$.

Experimental procedure. For each species, $1,3,5$, or 10 buds were placed in $180-\mathrm{mL}$ glass jars (8/treatment) containing $30 \mathrm{~mL}$ of medium solidified with $0.07 \%$ agar (Plant Tissue Culture Grade Agar A111, PhytoTechnology Labs, Shawnee Mission, Kan.). Buds were planted in agar medium with careful attention to uniform spacing within the jar and basipetal insertion in the semi-solid gel. For liquid medium, buds were cut, trimmed, 
Table 1. Effects of culture system, type of medium, and explant density on Alocasia macrorrhizos growth after 4 weeks of micropropagation.

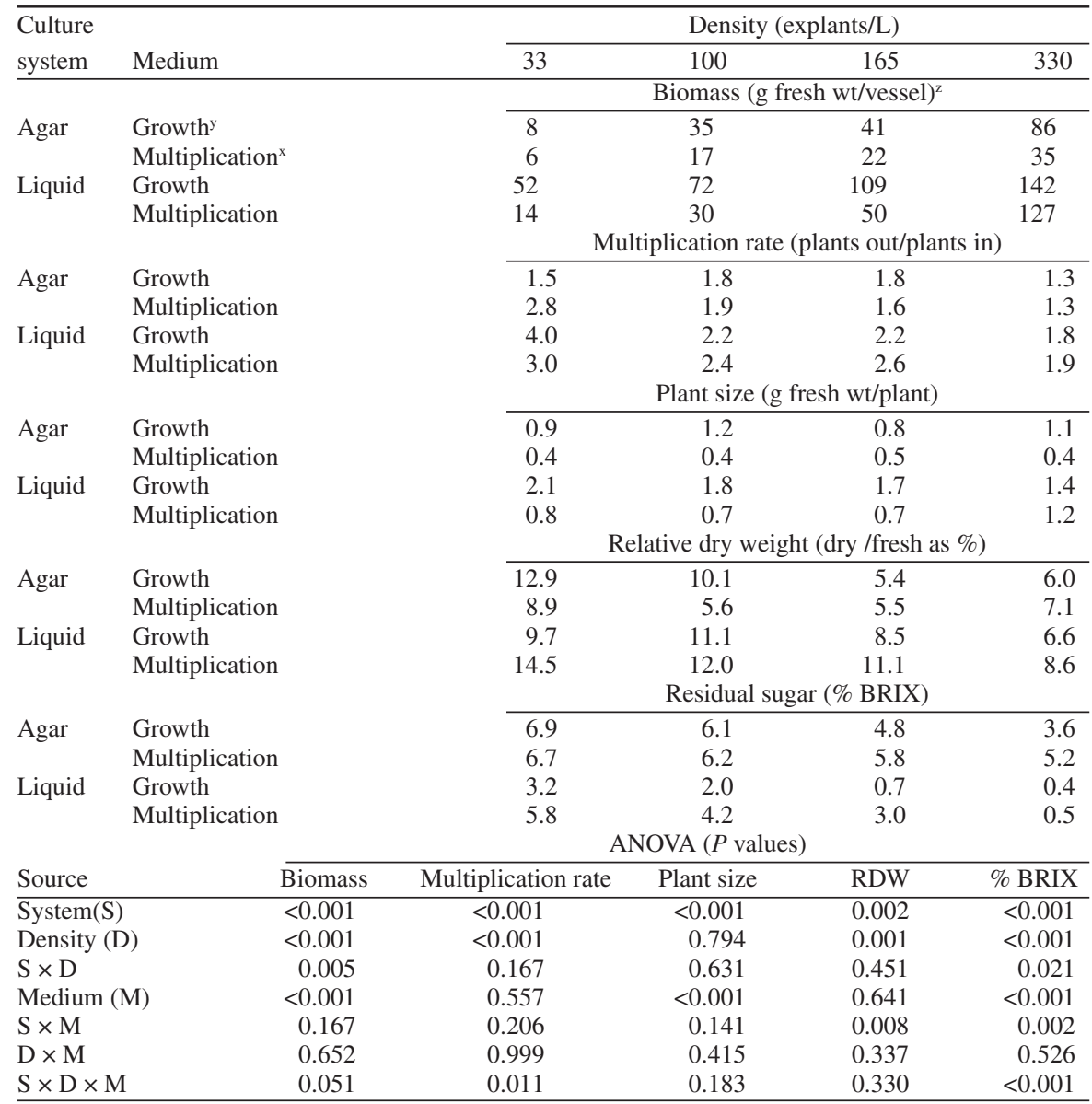

${ }^{2}$ For agar medium, fresh weight was multiplied by 6 to adjust for different media volume.

${ }^{\mathrm{y}}$ Growth medium contained $1 \mu \mathrm{M}$ BA.

${ }^{\mathrm{y}}$ Multiplication medium contained $3 \mu \mathrm{m}$ ancymidol and $3 \mu \mathrm{M}$ BA.

and collected in sterile jars (with 6, 18, 30, or 60 buds/jar). For each variety, four rocker vessels (Southern Sun BioSystems, Hodges, S.C.) containing $180 \mathrm{~mL}$ of liquid medium were prepared for each density treatment. Cut buds were dumped into a rocker vessel with one motion and without regard to orientation or spacing. The densities correspond to 33, 100,165 and 330 buds/L of medium for each system. The $180-\mathrm{mL}$ glass jar containing $30 \mathrm{~mL}$ of medium represents a standard practice in agar culture, and it was compared with a dissimilar proportioned rectangular vessel of liquid. Two media differing in their plant growth regulator content were used. Growth medium with $1 \mu \mathrm{M}$ BA (as above) was compared to a multiplication medium containing $3 \mu \mathrm{M}$ BA and $3 \mu \mathrm{M}$ of the growth inhibitor, ancymidol. Plants were grown for four weeks under the environmental conditions previously described.

After 4 weeks, plants were carefully blotted on paper towels and fresh weight per vessel and the number of plants per vessel were recorded for all plant tissue in the experiment. Dry weight was also determined for all tissue from agar culture. An $\approx 10$-g sample of tissue was taken from each thin-film rocker vessel. Dry weight was recorded after drying the contents of each vessel individually in paper envelopes at $60{ }^{\circ} \mathrm{C}$ for $48 \mathrm{~h}$. Residual sugar in expended liquid media of each thin-film rocker vessel

2 media $\times 4$ planting densities with a factorial densities (initial explants per liter of medium). treatment structure. Data were collected for biomass yield (fresh weight), bud multiplication (number of plants harvested/number of explants initiated), plant size (fresh weight/ number of plants harvested), percent relative dry weight $(100 \times$ dry weight/fresh weight $)$ and residual sugar concentration (percent BRIX) for each vessel. Due to differences in vessel size for the two culture systems, it was necessary to multiply biomass yield per jar of agar by a scale-up factor of six to adjust for differences in medium volume (volume of vessels' headspace is related by a different factor). Factorial analysis of variance was performed to evaluate interaction and main effects of the treatment factors using $\alpha=0.05$. Factor interactions were examined by performing appropriate comparisons among the combination means using linear contrasts. Relationships of plant biomass and relative dry weight with residual sugar were examined using linear and exponential models.

\section{Results and Discussion}

Alocasia. Analysis of biomass production, residual sugar, and multiplication rate indicated three-factor interactions between growth system, medium type, and explant density (Table 1). Thus, the effects of growth system on these responses depended on explant density and medium used. The thin-film liquid system produced greater tissue fresh weight (biomass) than agar at all explant densities in each media. Biomass production increased curvilinearly (generally at an increasing rate) as explant density increased (Fig. 1) except for the multiplication medium in agar-based culture, which exhibited a linear increase. Growth medium in the thin-film liquid system accounted for the greatest biomass over the range of explant densities used, but a lower rate of increase in biomass was observed at the highest density. Improved growth in liquid systems has been reported on numerous occasions and may be attributed to the lack of impurities from agar, better water availability, better nutrient availability and larger vessels (Bethouly and Etienne, 2002; Smith and Spomer, 1995).

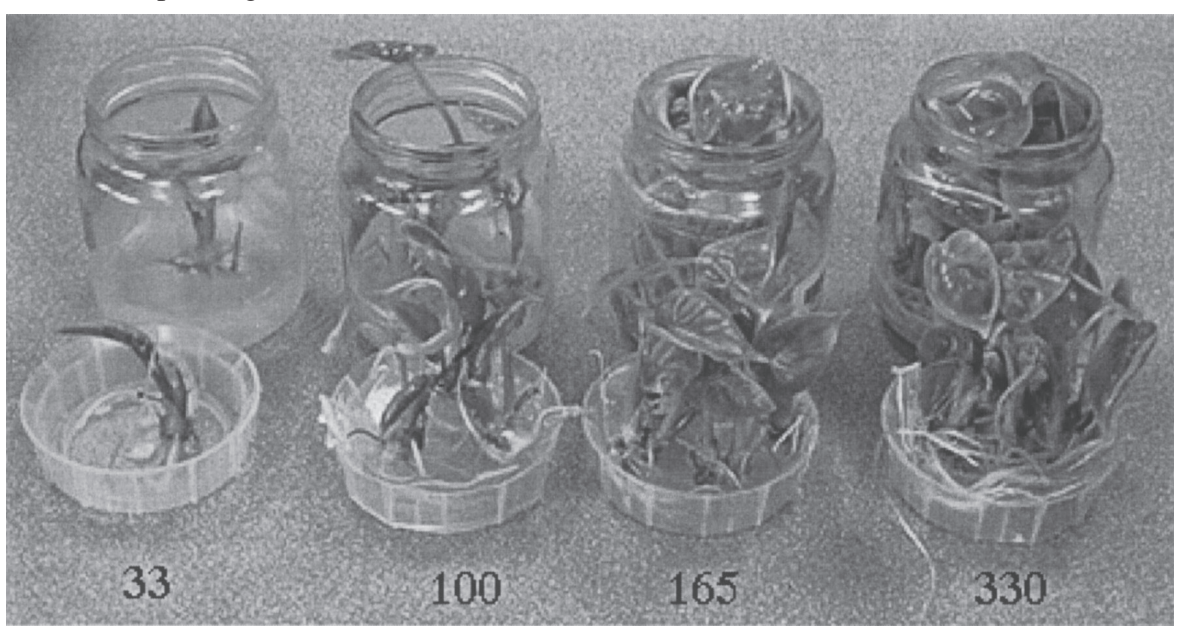

Fig. 1. Alocasia macrorrhizos after 4 weeks in jars of $1 \mu \mathrm{M}$ BA agar growth medium at different explant 


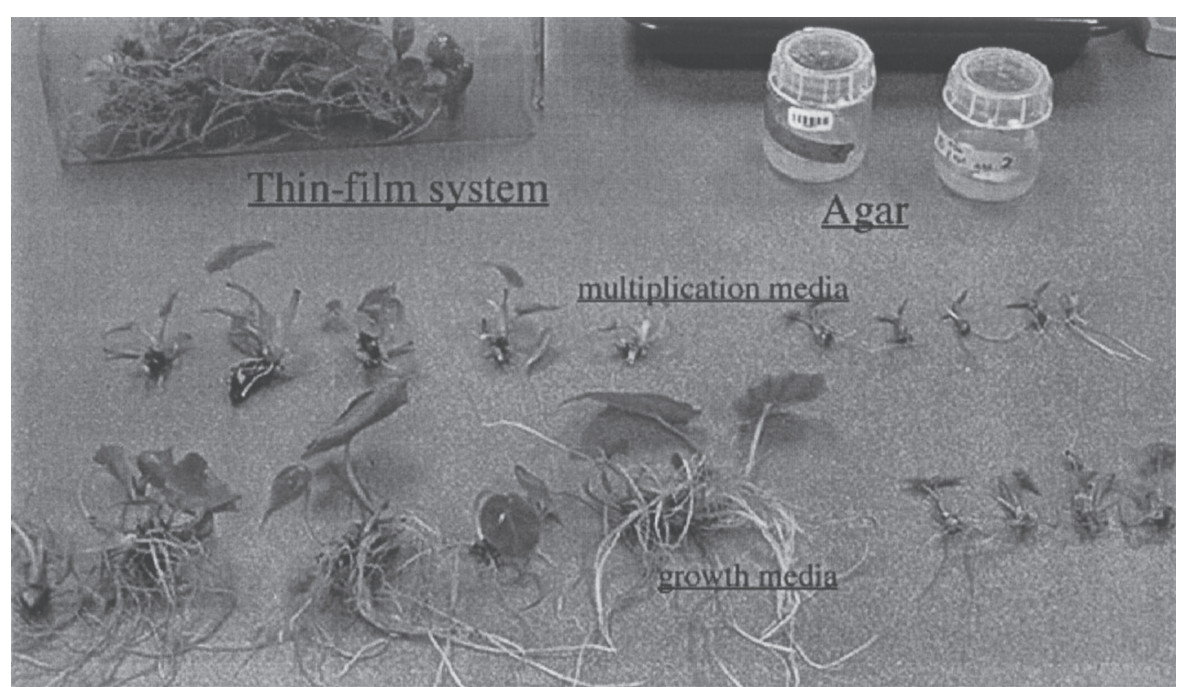

Fig. 2. Alocasia macrorrhizos after 4 weeks from a planting density of 165 explants/L media.

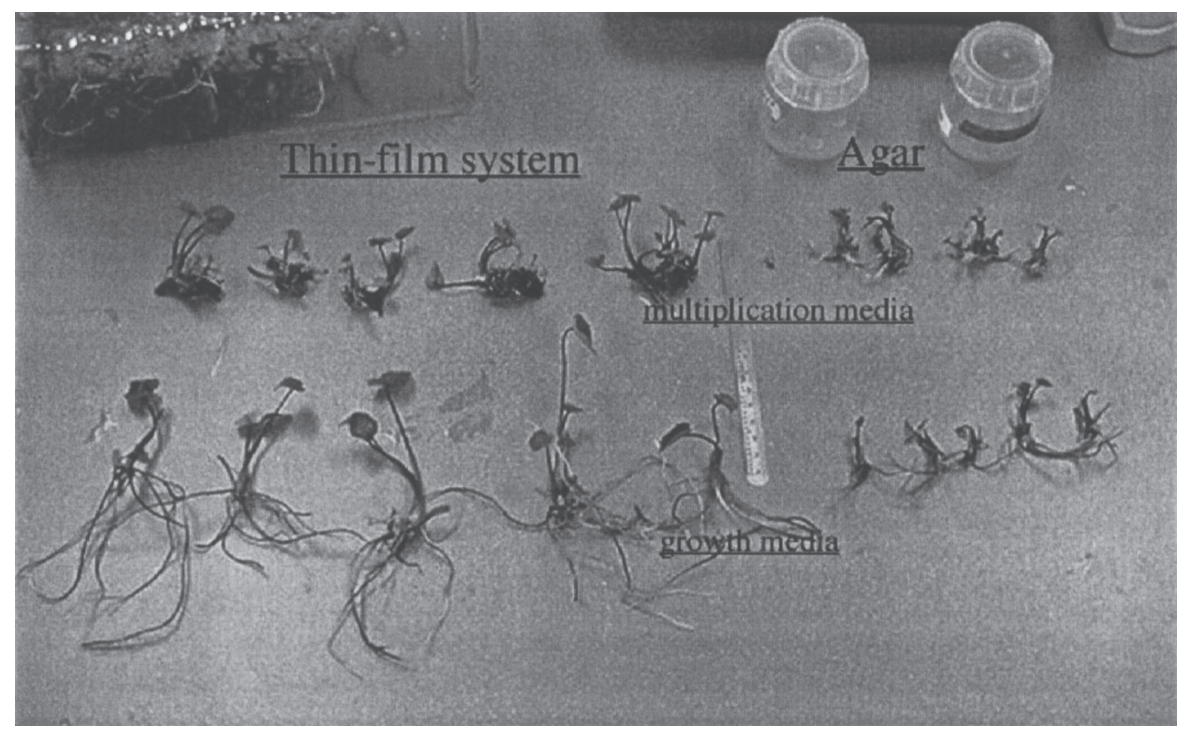

Fig. 3. Colocasia esculenta 'Fontanesii' after 4 weeks from a planting density of 165 explants/L media.

Residual sugar declined most rapidly as explant density increased in the thin-film liquid system with growth medium due to greater biomass production and was $<1 \%$ BRIX for 165 and 330 explants/L (Table 1). For multiplication medium in the thin-film liquid system, $<1 \%$ BRIX was observed for 330 explants/L. The refractometer is an inexpensive tool that rapidly measures sugar with minimal sample preparation. The limitation of this tool is that it measures BRIX, a molar summation of sucrose and its monomers, glucose and fructose, in the medium. At least three events can occur in tissue culture that will impact determination of sugar use by the plantlets: 1) a small fraction of sucrose hydrolyzes to glucose and fructose in the autoclave, 2) cell wall invertase hydrolyzes some sucrose to glucose and fructose and releases a portion of the monomers into the media, and 3) water uptake by growing plantlets increases the molar concentration of solution by decreasing the volume of diluent. All three will cause underestimation of sugar uptake when interpreting BRIX readings of residual media. HPLC separation of mono- and disaccharides or colorimetric reagents measure residual sugar more specifically. However, a refractometric assay of media, with zero reagent cost and realtime feedback, is a practical alternative that is preferable to working without information on sugar use. When comparing treatments within a controlled experiment, BRIX in residual media does provide a relative index of sugar use and indicates whether sugar depletion occurred during the culture cycle. erization or extent of water loss, we cannot accurately calculate moles of sugar residual or chemical energy remaining in media. However, sugar uptake is underestimated when assuming BRIX is expressed as sucrose concentration in original volume of medium. Sugar depletion is suspect at the high explant density in the thin-film liquid system when residual sugar dropped below 1\% BRIX. For the agar-based system, residual sugar declined to a lesser degree. Biomass production was also less in agar and at the highest explant densities, $3.6 \%$ and 5.2\% BRIX remained with growth and multiplication media, respectively. Sugar depletion did not limit growth in agar-based systems at any density tested.
Without assay of the degree of monom-
Alocasia macrorrhizos multiplied more rapidly in the thin-film system than on agar at all explant densities for each medium (Table 1). Multiplication rates were highest at the lowest explant density in the thin-film liquid system and declined linearly as density increased. For the agar-based system, multiplication rate declined linearly for the multiplication medium but was unaffected in the growth medium. Plant size was only affected by main effects of growth system and medium type with largest plants produced by the thin-film liquid system and growth medium (Fig. 2, Table 1). Plants averaged $1.3 \mathrm{~g}$ in the thin-film liquid compared to $0.7 \mathrm{~g}$ for the agar-based system and $1.4 \mathrm{~g}$ on growth media compared to $0.6 \mathrm{~g}$ in the multiplication media.

Analysis of relative dry weight indicated a two-factor interaction between culture system and medium type (Table 1). In the thin-film liquid system, relative dry weight averaged $11.6 \%$ for the multiplication medium and $9 \%$ for the growth medium; whereas, for the agarbased system, relative dry weight was greater for the growth medium (8.6\%) than for the multiplication medium $(6.8 \%)$. Thus relative dry weights were comparable for the two culture systems when growth medium was used but was considerably greater in the thin-film liquid system for multiplication medium. Increasing explant density generally reduced relative dry weight in each culture system. This may be due to competition for solutes in the medium or for space and light in the vessel. However, the smaller plants on multiplication media had much less fresh biomass, used less water from the medium, and yet they showed reduced relative dry weight at the highest density. Therefore a depletion of medium solutes (e.g. sugar) was likely limiting dry matter accumulation at the highest explant density, and not competition for water, space or light.

Colocasia. Analysis of biomass production, residual sugar, multiplication rate, and plant size indicated three-factor interactions between growth system, medium type, and explant density (Table 2), so the effects of growth system depended on explant density and type of medium used. Biomass was greater in the thin-film liquid than agar, and the differential between culture systems increased with explant density. Biomass increased curvilinearly (generally at an increasing rate) in the thin-film liquid system for each medium as explant density increased, and greater biomass was produced by the growth medium. For agar-based culture, a linear increase in biomass production was observed for each medium with greater growth occurring in the multiplication medium.

Residual sugar declined most dramatically as explant density increased in the thin-film bioreactor system regardless of medium and was $<1 \%$ BRIX with 330 explants per liter (Table 2). For the agar-based system, residual sugar declined to a lesser extent due to lowered biomass production and was $4.9 \%$ and $5.5 \%$ BRIX for growth and multiplication media, respectively, at the highest explant density. Residual BRIX in semi-solid agar medium following culture was generally higher than the 
Table 2. Effects of culture system, type of medium, and explant density on Colocasia esculenta 'Fontanesii' growth after 4 weeks of micropropagation.

\begin{tabular}{|c|c|c|c|c|c|c|}
\hline \multirow{2}{*}{$\begin{array}{l}\text { Culture } \\
\text { system }\end{array}$} & \multirow{2}{*}{\multicolumn{2}{|c|}{ Medium }} & \multicolumn{4}{|c|}{ Density (explants/L) } \\
\hline & & & 33 & 100 & 165 & 330 \\
\hline & & & \multicolumn{4}{|c|}{ Biomass $(\mathrm{g} \text { fresh wt/vessel })^{\mathrm{x}}$} \\
\hline \multirow{2}{*}{ Agar } & \multicolumn{2}{|c|}{ Growth $^{y}$} & 2 & 7 & 7 & 22 \\
\hline & \multicolumn{2}{|c|}{ Multiplication $^{2}$} & 2 & 12 & 20 & 30 \\
\hline \multirow[t]{3}{*}{ Liquid } & \multirow{2}{*}{\multicolumn{2}{|c|}{$\begin{array}{l}\text { Growth } \\
\text { Multiplication }\end{array}$}} & 3 & 52 & 62 & 158 \\
\hline & & & 9 & 30 & 52 & 101 \\
\hline & & & \multicolumn{4}{|c|}{ Multiplication rate (plants out/ plants in) } \\
\hline \multirow[t]{2}{*}{ Agar } & \multicolumn{2}{|c|}{ Growth } & 2.3 & 1.8 & 1.7 & 1.2 \\
\hline & \multicolumn{2}{|c|}{ Multiplication } & 2.3 & 3.4 & 2.7 & 1.8 \\
\hline \multirow[t]{3}{*}{ Liquid } & Gr & & 2.3 & 1.6 & 2.0 & 1.4 \\
\hline & \multicolumn{2}{|c|}{ Multiplication } & 4.0 & 2.4 & 3.1 & 2.0 \\
\hline & & & \multicolumn{4}{|c|}{ Plant size (g fresh wt/plant) } \\
\hline \multirow[t]{2}{*}{ Agar } & \multicolumn{2}{|c|}{ Growth } & 0.2 & 0.3 & 0.2 & 0.3 \\
\hline & \multicolumn{2}{|c|}{ Multiplication } & 0.2 & 0.2 & 0.3 & 0.3 \\
\hline \multirow[t]{3}{*}{ Liquid } & \multirow{2}{*}{\multicolumn{2}{|c|}{$\begin{array}{l}\text { Growth } \\
\text { Multiplication }\end{array}$}} & 0.2 & 1.9 & 1.3 & 1.8 \\
\hline & & & 0.4 & 0.7 & 0.6 & 0.8 \\
\hline & & & \multicolumn{4}{|c|}{ Relative dry weight (dry/fresh as \%) } \\
\hline \multirow{2}{*}{ Agar } & \multicolumn{2}{|c|}{ Growth } & 8.8 & 9.5 & 9.1 & 7.7 \\
\hline & \multirow{2}{*}{\multicolumn{2}{|c|}{$\begin{array}{l}\text { Multiplication } \\
\text { Growth }\end{array}$}} & 10.2 & 10.9 & 10.2 & 8.6 \\
\hline \multirow[t]{3}{*}{ Liquid } & & & 13.8 & 8.6 & 6.4 & 4.5 \\
\hline & \multirow{2}{*}{\multicolumn{2}{|c|}{ Multiplication }} & 14.1 & 10.5 & 8.1 & 6.3 \\
\hline & & & \multicolumn{4}{|c|}{ Residual sugar (\% BRIX) } \\
\hline Agar & $\mathrm{Gr}$ & & 7.3 & 7.1 & 7.0 & 5.5 \\
\hline & $\mathrm{Mu}$ & & 7.3 & 6.0 & 5.3 & 4.9 \\
\hline Liquid & $\mathrm{Gr}$ & & 7.4 & 2.6 & 2.7 & 0.8 \\
\hline & $\mathrm{Mu}$ & & 6.1 & 4.0 & 2.1 & 0.9 \\
\hline & & & & OVA $(P$ val & & \\
\hline Source & & Biomass & Multiplication rate & Plant size & RDW & $\%$ BRIX \\
\hline System & & $<0.001$ & 0.115 & $<0.001$ & 0.390 & $<0.001$ \\
\hline Density & & $<0.001$ & $<0.001$ & $<0.001$ & $<0.001$ & $<0.001$ \\
\hline$S \times D$ & & $<0.001$ & 0.002 & $<0.001$ & $<0.001$ & $<0.001$ \\
\hline Mediun & & 0.023 & $<0.001$ & $<0.001$ & 0.001 & 0.005 \\
\hline $\mathrm{S} \times \mathrm{M}$ & & $<0.001$ & 0.377 & $<0.001$ & 0.810 & 0.026 \\
\hline $\mathrm{D} \times \mathrm{M}$ & & 0.004 & 0.325 & 0.003 & 0.908 & 0.045 \\
\hline $\mathrm{S} \times \mathrm{D} \times$ & & 0.001 & 0.007 & 0.007 & 0.823 & 0.001 \\
\hline
\end{tabular}

${ }^{2}$ For agar medium, fresh weight was multiplied by 6 to adjust for different media volume.

${ }^{y}$ Growth medium contained $1 \mu \mathrm{M}$ BA.

${ }^{\mathrm{x}}$ Multiplication medium contained $3 \mu \mathrm{m}$ ancymidol and $3 \mu \mathrm{M}$ BA.

$5 \%$ supplied in the medium, a likely result of significant water uptake and/or monomerization of sugars.

Multiplication rates were highest at the lowest explant density in the thin-film liquid system with multiplication medium and declined linearly as density increased (Table 2), while multiplication rates were generally lower and unaffected by density in the growth medium in the thin-film liquid system. For the agar-based system, multiplication rate responded quadratically (increasing up to about 100 explants per liter and then declining) in the multiplication medium as density increased, while it declined linearly as density increased for the growth medium.

The liquid culture system produced larger Colocasia plants than agar-based system except at the lowest density, 33 explants per liter (Table 2). Agar-cultured plants averaged $<0.3$ $\mathrm{g}$ for all densities in both media, while plants grown in thin-film culture averaged 0.7 and $1.7 \mathrm{~g}$ in multiplication and growth medium, respectively, over the density range of 100 to 330 explants/L (Fig. 3 and Table 2).

Analysis of relative dry weight indicated a two-factor interaction between culture system and explant density (Table 2). Relative dry weight was highest $(14 \%)$ at the lowest explant density in the thin-film liquid system and declined linearly as density increased. For agar culture, relative dry weight increased as density increased to 100 explants/L and then declined as explant density increased further. In agar, there was a main effect of medium type on relative dry weight with the multiplication media averaging $9.9 \%$ compared to $8.5 \%$ for the growth medium.

Growth versus residual sugar. An exponential model (Fig. 4) characterized the relationship between biomass and residual sugar for each culture system (combining results for the two species and two media). More sugar was available to explants for greater biomass increase in the thin-film liquid than with agar-based system, but more sugar was used to produce comparable biomass by the thin-film liquid than with agar-based culture. It was also apparent that sugar depletion can become a limitation to growth when the greatest biomass was produced in high density, thinfilm liquid culture.

Relative dry matter content was linearly related to residual sugar for the thin-film liquid (Fig. 5). For each $1 \%$ increase in residual sugar there was a $1.1 \%$ increase in relative dry weight. Plants in the lower range of relative dry weight $(<5 \%)$ were from media with $<1 \%$ residual sugar. If a minimum relative dry matter content is necessary to confer plant quality, supplemental sugar in high-density thin-film cultures may be effective. The relationship between residual sugar and relative dry matter was not significant for agar culture. It is unlikely that the relative dry matter of plants in agar culture would be increased by additional sugar in the medium.

Hyperhydricity, a lowered tissue quality from excessive uptake of free water, was prevented by a variety of mechanical devices that facilitated greater growth with liquid medium (Smith and Spomer, 1995). Plants grown in TIS systems do not become hyperhydric when immersion cycles are correctly timed (Etienne and Bethouly, 2002). Hyperhydric elephant ears were not observed in 2 years of research in thin-film liquid culture systems before this study using a 1-min immersion cycle every 15 min (Adelberg, unpublished). Thousands of elephant ear plants from these prior cycles were

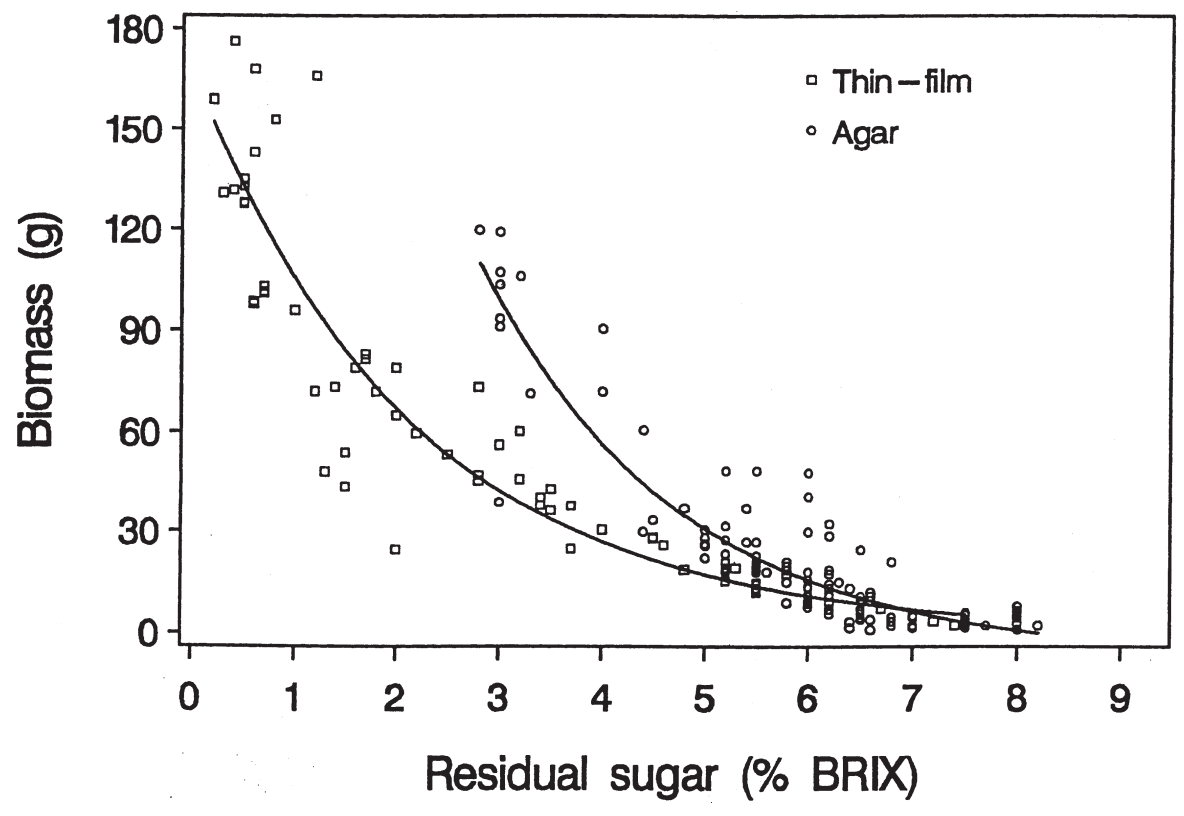

Fig. 4. Correlation of residual sugar in media and biomass (fresh weight per vessel adjusted for scale-up) after 4 weeks of growth for Alocasia and Colocasia. Thin-film: y $=1.66 .6 \mathrm{e}-0.455 \mathrm{x}\left(r^{2}=0.85\right)$. Agar: $\mathrm{y}=-7.3+495 \mathrm{e}-0.513 \mathrm{x}\left(r^{2}=0.85\right)$. 


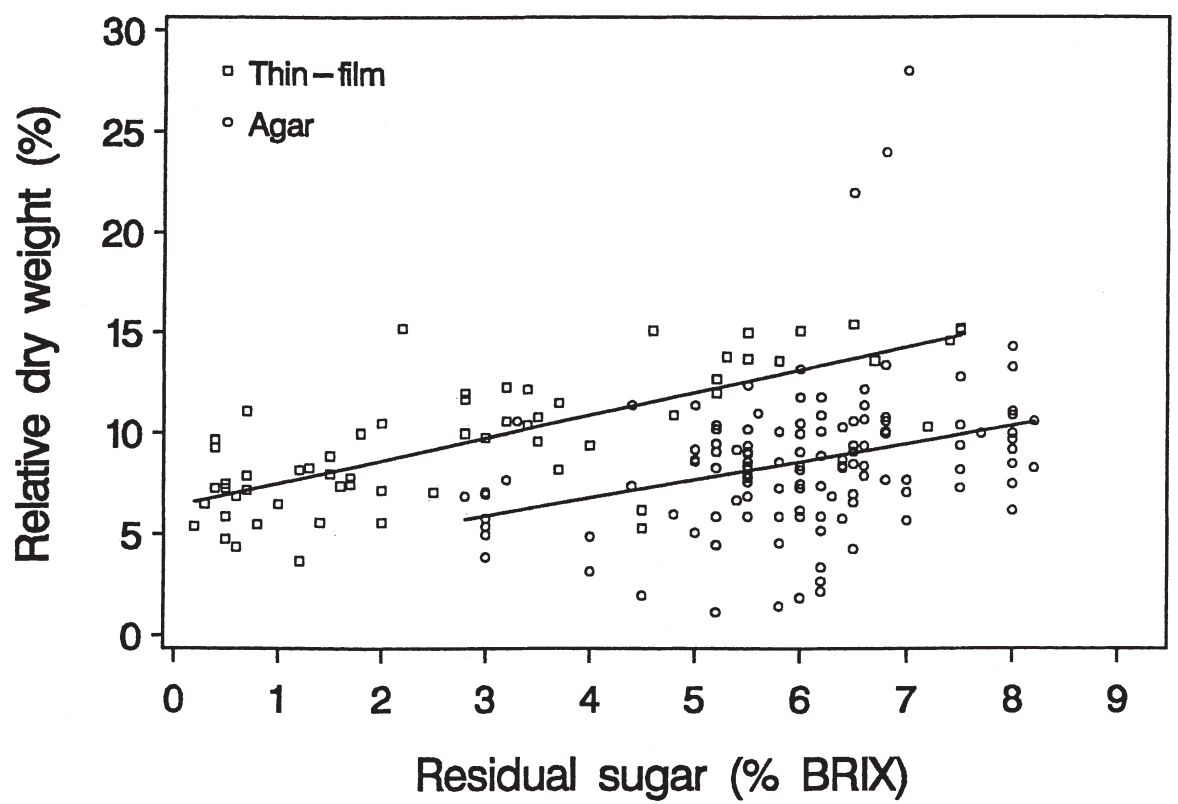

Fig. 5. Correlation of residual sugar in media and relative dry weight (dry weight/ fresh weight) after 4 weeks of growth for Alocasia and Colocasia. Thin-film: $\mathrm{y}=6.42+1.12 \mathrm{x}\left(r^{2}=0.56\right)$. Agar: $\mathrm{y}=3.24$ $+0.89 \mathrm{x}\left(r^{2}=0.10\right)$.

grown in mist-frame greenhouses at a commercial nursery. Acclimatization was reported by nursery staff to be very high. Four hundred and fifty plantlets of varying sizes grown at Clemson University Greenhouse Complex showed $>99 \%$ survival. We assume the larger plantlets would finish a saleable sized nursery container more quickly, although data was not collected to correlate laboratory plantlet size and nursery growth.

\section{Conclusion}

Micropropagation involves both plant growth and bud multiplication. Larger plants with greater dry weights were grown from thin-film liquid than agar with both species, dependent on plant density. The increased fresh biomass and relative dry weight was related to an increased availability of sugars from the medium. The relationship between sugaruptake and cell growth has been documented for suspended cells in fermentation-type bioreactors but has

\section{Literature Cited}

Adelberg, J. 2004. Efficiency in thin-film liquid system for micropropagtion of Hosta. Plant Cell Tiss. Org. Cult. (in press).

Adelberg, J. and E.P. Simpson. 2002. Intermittent Immersion Vessel Apparatus and Process for Plant Propagation. US patent pending, Publ. US 2002/0155595 A1.

Avent, T. 2001. Aroid hardiness list. Intl. Aroid Soc. 13 Jan. 2003. <http://www.aroid.org/horticulture. $\mathrm{html} / \mathrm{s}$.

Chand, H., M.N. Pearson, and H. . Lovell. 1999. Rapid vegetative mulitplication in Colocasia esculenta (L) Schott (taro). Plant Cell Tiss. and Org. Cult. 55:223-226.

Desjardins, Y., C. Hdider, and J. DeRiek. 1995. Carbon nutrition in vitro, regulation and manipulation of carbon assimilation in the micropropagation process, p. 441-472. In: J. Aitken-Christie, T. Kozai, and M.A.L. Smith (eds.). Automation and environmental control in plant tissue culture. Kluwer Academic, Dordecht, The Netherlands.

Etienne, H. and M. Berthouly. 2002. Temporary immersion systems in plant micropropagation. Plant Cell Tiss. Org. Cult. 69:215-231.

Murashige, T. and F. Skoog. 1962. A revised media for rapid growth and bioassays with tobacco cultures. Physiol. Plant. 15:473-497.

Gollagunta, V., J.Adelberg, J. Rieck, and N. Rajapakse. 2004. Sucrose concentration in liquid media affects soluble carbohydrates, biomass and storage quality of micropropagated Hosta. Plant Cell Tiss. Org. Cult. 77:125-131.

Hale S.A., R. Young, J. Adelberg, R, Keese, and D. Camper. 1992. Bioreactor development for continual-flow, liquid plant tissue culture. Acta Hort. 319:107-112.

Harris R.E, and E.B. Mason. 1983. Two machines for in vitro propagation in liquid media. Can. J. Plant Sci. 63:311-316.

Levin, R., and G. Tanny. 2003. Bioreactors as a low cost option for tissue culture, Chapter6.In: B.Ahloowalia (ed.). Low cost options in tissue culture for developing countries. IAEA TecDoc, Intl. Atomic Energy Agency, Vienna, Austria. (in press)

Smith, M.A.L. and L.A. Spomer. 1995. Vessels, gels, liquid media and support systems, p. 371-404. In: J. Aitken-Christie, T. Kozai, and M.A.L. Smith (eds.). Automation and environmental control in plant tissue culture. Kluwer Academic, Dordecht, The Netherlands.

Trujilo, E.E. 2002. Taro plant named 'Pa Akala'. U.S. Patent PP12,772 P2

Zhou, S.P., Y.K. He, and S.J. Li. 1999. Induction and characterization of in vitro corms of diploid taro. Plant Cell Tiss. Org. Cult. 57:173-178. 